\title{
ĐỀ XUẤT YÊU CẦU VỀ Độ CHÍNH XÁC TRONG ĐO ĐẠC CHİNH LÝ BẢN ĐỒ ĐỊA CHÍNH SỐ
}

\author{
LÊ VIÉT NAM, NGUYẼ̃N THANH THUỶ, NGUYẼN PHI SO'N \\ Viện Khoa học Đo đạc và Bản đồ
}

\section{Tóm tắt}

Phép đo chỉnh lý biến động là phép đo có điều kiện, nhằm đạt được độ chính xác cao nhất về diện tích hay về cạnh thửa thông qua các tọa độ đỉnh thửa. Tuy nhiên, khi sử dụng các điểm khởi đo như quy định hiện nay thì điểm góc thửa biến động luôn chứa sai số đo vẽ thành lập bản đồ gốc và sai số của phép đo biến động, 2 dữ liệu này thuộc 2 phép đo không cùng điều kiện. Trong bài báo này sẽ đưa ra cơ sở để tính toán và đề xuất yêu cầu độ chính xác của đo biến động và làm cơ sở cho đồng bộ dữ liệu biến động. Kết quả đề xuất ở bài báo này là sản phẩm của Đề tài cấp Bộ "Nghiên cứu đề xuất các yêu cầu kỹ thuật trong chỉnh lý bản đồ địa chính gắn với giải pháp xây dụnng CSDL địa chính".

\section{Giới thiệu}

Chỉnh lý biến động đất đai là việc thực hiện những thủ tục ghi nhận các thay đổi về không gian và thông tin thuộc tính về thửa đất so với hồ sơ địa chính đã đăng ký theo quy định của pháp luật. Đo đạc biến động là một phần việc của công tác này. Đo đạc biến động và chỉnh lý bản đồ địa chính đã được quy định tại một số văn bản như Thông tư 09/2007/TT-BTNMT ngày 02/08/2007 hướng dẫn việc lập, chỉnh lý, quản lý hồ sơ địa chính; Thông tư $30 / 2013 /$ TT-BTNMT ngày $14 / 10 / 2013$ quy định thực hiện lồng ghép việc đo đạc lập hoặc chỉnh lý bản đồ địa chính và đăng ký, cấp giấy chứng nhận quyền sử dụng đất, quyền sở hữu nhà ở và tài sản khác gắn liền với đất, xây dựng hồ sơ địa chính, cơ sở dữ liệu địa chính; Thông tư 24/2014/TT-BTNMT ngày 19/5/2014 quy định về hồ sơ địa chính và Thông tư 25/2014/TT-BTNMT ngày 19/5/2014 quy định về thành lập bản đồ địa chính. Các thông tư này đã hướng dẫn và quy định về yêu cầu, nội dung, trình tự thủ tục chỉnh lý bản đồ và hồ sơ địa chính. Các vấn đề về đo đạc biến động và chỉnh lý bản đồ địa chính đã được quy định bởi Thông tư 25/2014/TT-BTNMT. Theo đó, độ chính xác đo đạc biến động được quy định bằng độ chính xác đo vẽ thành lập bản đồ địa chính theo tỷ lệ tương ứng. Tuy nhiên vấn đề đặt ra ở đây khi đo chỉnh lý, cho phép sử dụng các điểm khởi tính từ lưới khống chế đo vẽ, Iưới điểm trạm đo cũ, điểm góc thửa đất, góc công trình xây dựng có trên bản đồ và hiện còn tồn tại ở thực địa...nhưng thực tế các điểm khởi tính này gần như không còn ở thực địa, nhất là sử dụng các điểm góc thửa hay góc công trình xây dựng làm điểm khởi đo biến động sẽ ảnh hưởng nhiều đến độ chính xác khi chỉnh lý bản đồ và đồng bộ dữ liệu biến động. Thực tế khi đo biến động khu vực đơn lẻ hoặc một vài thửa đất, thường dùng góc thửa ổn định làm cơ sở để đo các điểm biến động, khu vực biến động lớn, nhiều thửa thay đổi hay phân chia lại đất đai thường phải xây dựng lưới khống chế đo vẽ biến động...như vậy cho dù phải lập lưới khống chế đo chỉnh lý mới hay sử dụng các điểm góc thửa, góc công trình ổn định thì chúng ta có thể thấy rằng phép đo biến động và phép đo thành lập bản đồ gốc là những phép đo không cùng điều kiện 
(không cùng thời điểm đo, không cùng thiết bị đo, không cùng điểm khởi đo...). Theo lý thuyết, khi hai phép đo có cùng độ chính xác như nhau nhưng khác điều kiện thì sai số so với cấp khống chế gần nhất sẽ giảm $\sqrt{2}$ lần. Khi đo biến động chúng ta có thể đo với độ chính xác rất cao dựa trên một điều kiện nhất định nào đó nhưng khi tiếp ghép dữ liệu đo biến động vào dữ liệu gốc đều chứa sai số, vấn đề là sai số này là bao nhiêu để khi đồng bộ (tiếp ghép) trên dữ liệu số các điểm song trùng phải trùng nhau (sai số coi như bằng không khi tiếp biên dữ liệu số). Trong bất kỳ trường hợp nào khi đo biến động đối với các thửa còn dấu mốc góc thửa hay không còn dấu mốc góc thửa đều chứa đựng sai số gồm: $m_{\text {đoBĐgoc }}$ sai số của đo vẽ thành lập bản đồ; $m_{\text {đoBienđong }}$ sai số của đo biến động. Các yêu cầu sai số $m_{\text {đoBĐgoc }}$ và $m_{\text {đoBienđong }}$ đều được quy định là sai số so với cấp khống chế đo vẽ gần nhất. Như vậy SSTB hay nói cách khác khoảng cách sai lệch giữa tọa độ điểm đo biến động so với điểm song trùng tương ứng là bao nhiêu thì có thể đồng nhất 2 điểm này là một. Dưới đây sẽ đưa ra cơ sở để tính yêu cầu sai số vị trí điểm đo biến động và sai số vị trí tương hỗ tại các điểm song trùng để tiếp ghép dữ liệu biến động vào dữ liệu gốc khi chỉnh lý vào bản đồ gốc dạng số hoặc CSDL địa chính có thể tự động trùng điểm mà không ảnh hưởng đến các thửa lân cận không biến động.

\section{Cơ sở xây dựng yêu cầu độ chính xác trong đo đạc biến động}

Khi đo đạc thành lập bản đồ địa chính cần đảm bảo yêu cầu về độ chính xác quy định về sai số trung phương hoặc sai số trung bình giữa các trị đo và trị kiểm tra đã được quy định cho từng tỷ lệ bản đồ khác nhau. Đo đạc biến động có đặc thù là các phép đo có điều kiện, bên cạnh yêu cầu về độ chính xác đo đạc tương tự như đo vẽ thành lập còn có những điều kiện bắt buộc khi chia tách, gộp, hiệu chỉnh thửa đất theo các điều kiện về cạnh cho trước, diện tích cho trước, vị trí đỉnh thửa cho trước, đây là những số liệu mà chủ sử dụng đất biết rất rõ. Bên cạnh đó khi đo đạc biến động chúng ta cần phải thực hiện các phép đo song trùng, để đưa dữ liệu biến động về trùng với dữ liệu gốc... Vì vậy, để đưa ra được tiêu chuẩn độ chính xác đo chỉnh lý biến động thửa đất nhất thiết phải xuất phát từ quan hệ giữa điều kiện diện tích, điều kiện cạnh với độ chính xác đo đạc, có nghĩa rằng độ chính xác đo chỉnh lý phải đạt được ở mức độ nào để sai số diện tích sau chỉnh lý hay cạnh sau chỉnh lý phải nằm trong một điều kiện mà các bên liên quan đến thửa đất biến động chấp nhận được.

Ví dụ về các điều kiện như: trường hợp biến động lớn, phân chia lại đất đai, dồn điền đổi thửa, cần chỉnh lý hàng loạt thửa đất, khi đó một khối các thửa đất cần được chỉnh lý phải đảm bảo các thửa sau biến động phải có diện tích bằng diện tích pháp lý ban đầu. Do đó, điều quan trọng là coi khối như là một đơn vị xử lý cơ bản trong việc điều chỉnh diện tích thửa. Vì vậy, nếu các thửa đất được hiệu chỉnh riêng biệt mà không tính đến mối tương quan giữa chúng, thì ranh giới giữa các thửa đất này có thể chồng lên nhau. Ví dụ, Hình $1 a$ cho thấy 3 thửa đất liền kề có cùng một số ranh giới chung. Nếu chúng ta điều chỉnh từng lô một các ranh giới chung của các thửa được điều chỉnh sẽ chồng lên nhau và không phù hợp với nhau. Ở đây, chúng ta đang giải quyết vấn đề không thống nhất giữa tọa độ đo biến động và dữ liệu gốc, sự chồng chéo này không được chấp nhận. (xem hinh 1)

Giả sử thửa đất ban đầu trước biến động có diện tích là $P$, Theo [1] thì $m_{P}$ được xác định với độ chính xác phụ thuộc vào độ chính xác đo tọa độ các đỉnh thửa tại phương trình (1),

$$
m_{P}=m_{x y} \cdot \sqrt{1 / 8 \sum_{i=1}^{n} d_{i}^{2}}
$$



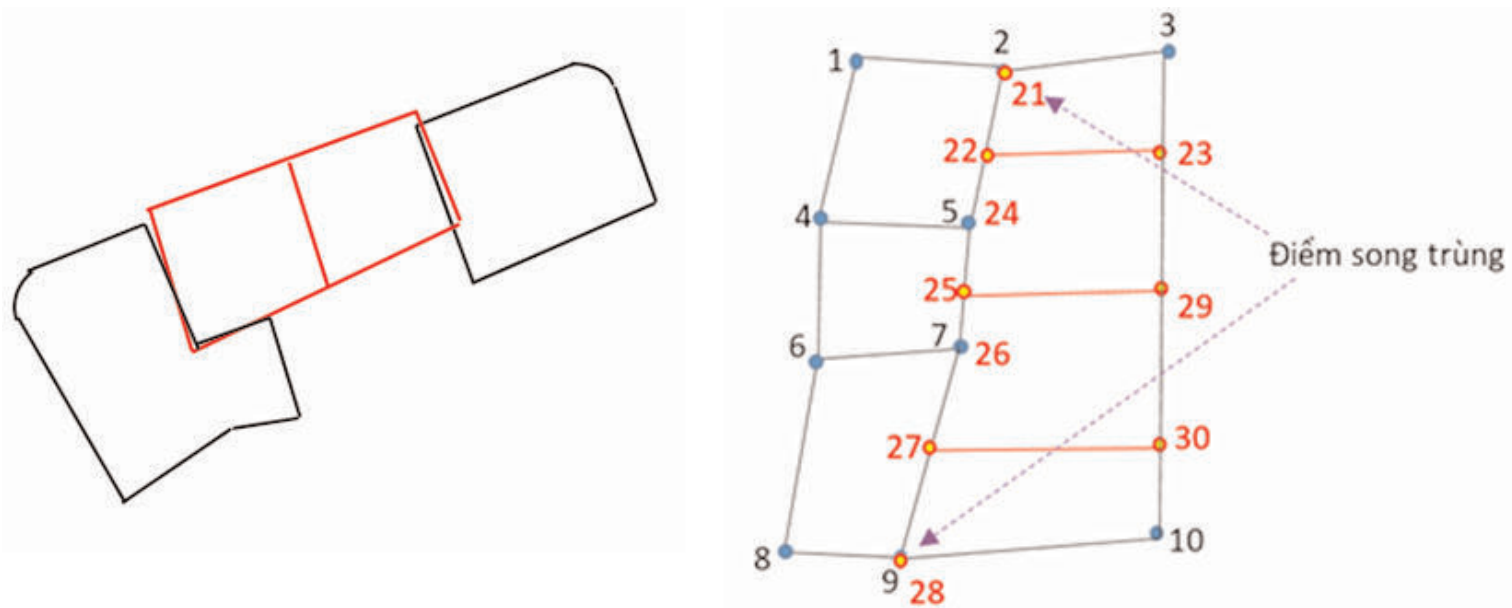

Hình 1: Dữ liệu đo biến động khi tiếp ghép với dữ liệu gốc

Trong đó $m_{x y}$ là sai số trung phương xác định tọa độ đỉnh thửa, $d_{i}$ là khoảng cách giữa đỉnh $i-1$ đến $i+1$

Khi thửa đất có dạng hình chữ nhật, có hệ số chiều dài/chiều rộng $d_{1} / d_{2}=a / b=k$ thì công thức (1) được viết lại là:

$m_{P}^{2}=\frac{1}{8} 4\left(d_{1}^{2}+d_{2}^{2}\right) m_{x y}^{2}=\frac{1}{2}\left(d_{1}^{2}+k^{2} d_{1}^{2}\right) m_{x y}^{2}=\frac{1}{2} d_{1}^{2}\left(1+k^{2}\right) m_{x y}^{2}$

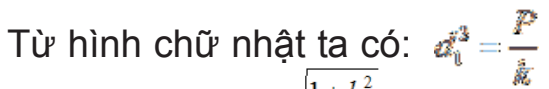

vì vậy: $m_{P}=m_{x y} \sqrt{P} \sqrt{\frac{1+k^{2}}{2 k}}$

Trong trường hợp hình dạng thửa đất là đa giác bất kỳ, để xác định hệ số kéo dài $k$ ta sử dụng chu vi $D$ của đa giác và chiều rộng tối đa của nó là $d$. Sau đó, tỷ lệ này $\left(\frac{D}{2}-d\right) / d$ có thể đại diện cho các hệ số kéo dài $k$.

Công thức (2) là quan hệ giữa sai số diện tích thửa được xác định thông qua công thức đánh giá độ chính xác tọa độ của các điểm trên ranh giới thửa đất.

Trong các tài liệu [2], [3], đã đưa ra điều kiện về sai số diện tích tính được sau biến động của thửa đất chia tách, phân chia lại nhiều thửa đất hay gộp thửa...., tùy theo loại đất điều kiện sai số diện tích phải đạt từ $0,1 \%$ đến $0,5 \%$ lần lượt cho đất tại đô thị đến đất lâm nghiệp, hay $m_{p}=0,001 . P \div$ 0,005.P, khi đó sai số về tọa độ $m_{x y}$ trong phép đo biến động tính từ công thức (2) có thể ước tính độ chính xác đo chỉnh lý biến động theo các tỷ lệ bản đồ như sau:

- $P$ : diện tích trung bình của thửa đất theo tỷ lệ tương ứng với mật độ thửa đã hướng dẫn tại TT25/2014/TT-BTNMT;

- $m_{p} \leq 0,005^{*} \mathrm{P}$. Giả sử lấy $k=5$ là thửa đất tiêu chuẩn.

Thay các giá trị $P, m_{p}, k$ vào (2) ta tính được $m_{x y}$ theo bảng. (xem bảng 1)

Từ Bảng 1 có thể thấy rằng khi đo biến động để đảm bảo độ chính xác của diện tích dưới $0,5 \%$ cho các tỷ lệ, thì yêu cầu độ chính xác vị trí khi đo biến động so với điểm khống chế đo vẽ gần nhất về lý thuyết phải đạt như cột (4) Bảng 1 ở trên.

Trên thực tế chúng ta đều biết rằng khi sử dụng các điểm khởi đo chỉnh lý là các điểm từ khống chế đo vẽ, điểm trạm đo, điểm góc thửa ổn định còn tồn tại ở thực địa...thì tại mỗi điểm góc thửa biến động luôn chứa sai số của phép đo bản đồ gốc và sai số của phép đo biến động. Vì vậy chúng 
ta có thể đưa ra công thức sai số vị trí tại điểm biến động nhận được là:

$m_{\text {DiemGocthuaBienDong }}=\sqrt{m_{\text {doBĐgoc }}^{2}+m_{\text {doBiendong }}^{2}}$
Trong đó:

- $m_{\text {đoBĐgoc }}$ là sai số đo vẽ thành lập bản (3) đồ gốc theo TT25/2014/TT-BTNMT.

Bảng 1: SSTP vị trí điểm trong đo biến động tính theo tỷ lệ bản đồ

\begin{tabular}{|c|c|c|c|}
\hline Tỷ lệ & Mật độ thửa & Diện tích trung bình $(\mathbf{P})$ & $\mathbf{m}_{x y}$ (cm) \\
\hline (1) & $(2)$ & $(3)$ & $(4)$ \\
\hline $1 / 200$ & 60 thửa/ha & $167 \mathrm{~m}^{2} /$ thửa & 4,0 \\
\hline \multirow{2}{*}{$1 / 500$} & 25 thửa/ha & $400 \mathrm{~m}^{2} /$ thửa & 5,7 \\
\cline { 2 - 4 } & 30 thửa/ha & $333 \mathrm{~m}^{2} /$ thửa & 8,8 \\
\hline \multirow{3}{*}{$1 / 1000$} & 40 thửa/ha & $250 \mathrm{~m}^{2} /$ thửa & 6,9 \\
\cline { 2 - 4 } & 20 thửa/ha & $500 \mathrm{~m}^{2} /$ thửa & 9,8 \\
\cline { 2 - 4 } & 10 thửa/ha & $1000 \mathrm{~m}^{2} /$ thửa & 13,9 \\
\hline \multirow{2}{*}{$1 / 2000$} & 10 thửa/ha & $2000 \mathrm{~m}^{2} /$ thửa & 13,9 \\
\cline { 2 - 4 } & 5 thửa/ha & $1000 \mathrm{~m}^{2} /$ thửa & 19,6 \\
\hline \multirow{2}{*}{$1 / 5000$} & $<1$ thửa/ha & $10.000 \mathrm{~m}^{2} /$ thửa & 43,9 \\
\hline & $>0,2$ thửa/ha & $40.000 \mathrm{~m}^{2} /$ thửa & 87,7 \\
\hline $1 / 10.000$ & $<0,2$ thửa/ha & $60.000 \mathrm{~m}^{2} /$ thửa & 107,4 \\
\hline
\end{tabular}

Bảng 2: Sai số vị trí điểm được đề xuất trong đo biến động

\begin{tabular}{|c|c|c|c|c|}
\hline Tỷ lệ & Loại đất & $\begin{array}{c}\text { SSTB - đo } \\
\text { biến động } \\
\text { theo } \\
\text { lý thuyết } \\
\left(\mathrm{m}_{\text {doBienĐong }}\right)\end{array}$ & $\begin{array}{l}\text { SSTB - đo } \\
\text { BĐồ gốc } \\
\text { theo thông } \\
\text { Tư 25 } \\
\left(\mathrm{m}_{\text {đoBĐgoc }}\right)\end{array}$ & $\begin{array}{c}\text { SSTB - đo } \\
\text { biến động } \\
\text { đề xuất } \\
\left(\mathrm{m}_{\mathrm{xyBienDong}}\right)\end{array}$ \\
\hline$(1)$ & $(2)$ & (3) & (4) & (5) \\
\hline $1 / 200$ & Đất thuộc nội thị của đô thị loại đặc biệt & $\pm 3,2$ & $\pm 5,0$ & $\pm 5,9 \mathrm{~cm}$ \\
\hline \multirow{2}{*}{$1 / 500$} & $\begin{array}{l}\text { Đất đô thị, đất khu đô thị, đất khu dân cư nông thôn có dạng } \\
\text { đô thị }\end{array}$ & $\pm 4,6$ & $\pm 7,0$ & $\pm 8,4 \mathrm{~cm}$ \\
\hline & Đất khu dân cư còn lại. & $\pm 7,0$ & $\pm 7,0$ & $\pm 9,9 \mathrm{~cm}$ \\
\hline \multirow{3}{*}{$1 / 1000$} & Thuộc đất khu dân cư & $\pm 5,5$ & $\pm 15,0$ & $\pm 16,0 \mathrm{~cm}$ \\
\hline & $\begin{array}{l}\text { Đất nông nghiệp có dạng thửa hẹp, kéo dài; đất nông nghiệp } \\
\text { trong phường, thị trấn, xã thuoộc các huyện tiếp giáp quận và } \\
\text { các xã thuộc thị xã, thành phố trực thuộc tỉnh }\end{array}$ & $\pm 7,8$ & $\pm 22,5$ & $\pm 23,8 \mathrm{~cm}$ \\
\hline & Đất nông nghiệp tập trung & $\pm 11,1$ & $\pm 22,5$ & $\pm 25,1 \mathrm{~cm}$ \\
\hline \multirow{2}{*}{$1 / 2000$} & Đất khu dân cư & $\pm 11,1$ & $\pm 30,0$ & $\pm 32,0 \mathrm{~cm}$ \\
\hline & Đất nông nghiệp & $\pm 15,7$ & $\pm 45,0$ & $\pm 47,7 \mathrm{~cm}$ \\
\hline \multirow[t]{2}{*}{$1 / 5000$} & $\begin{array}{l}\text { Đất sản xuất nông nghiệp, đất nuôi trồng thủy sản, đất làm } \\
\text { muối, đất nông nghiệp khác }\end{array}$ & $\pm 35,1$ & $\pm 150,0$ & $\pm 154,1 \mathrm{~cm}$ \\
\hline & Khu vực đất lâm nghiệp & $\pm 70,2$ & $\pm 150,0$ & $\pm 165,6 \mathrm{~cm}$ \\
\hline $1 / 10.000$ & $\begin{array}{l}\text { Đất lâm nghiệp, Đất chưa sử dụng, đất có mặt nước có diện } \\
\text { tích lớn trong trường hợp cần thiết đo vẽ để khép kín phạm } \\
\text { vi địa giới hành chính }\end{array}$ & $\pm 85,9$ & $\pm 300,0$ & $\pm 312,1 \mathrm{~cm}$ \\
\hline
\end{tabular}


- $m_{\text {đoBiendong }}$ là sai số của phép đo biến động được tính theo cách tiếp cận đảm bảo sai số diện tích $\left(m_{p} \leq 0,005^{*} \mathrm{P}\right)$ theo Bảng 1 .

Như vậy chúng ta có thể tính được yêu cầu sai số của điểm góc thửa biến động phải đạt được theo công thức (3). Lưu ý ở đây cần chuyển về sai số trung bình cho phù hợp với sai số đang quy định tại TT25/2014/TT-BTNMT. (xem bảng 2)

Đây cũng chính là sai số vị trí cho phép khi tiếp ghép dữ liệu đo biến động vào dữ liệu gốc ở dạng số hoặc chỉnh lý CSDL địa chính. Sai số này sẽ được đưa vào hạn sai trong thuật toán tự động trùng điểm trong chỉnh lý biến động đỉnh thửa của phần mềm chỉnh lý biến động ReCADAS1.0 của đề tài cấp Bộ "Nghiên cứu đề xuất các yêu cầu kỹ thuật trong chỉnh lý bản đồ địa chính gắn với giải pháp xây dựng CSDL địa chính".

\section{Kết luận}

Thực tiễn công tác đo đạc biến động đang cần nhiều quy định kỹ thuật hướng dẫn tác nghiệp chỉnh lý bản đồ địa chính, trong đó quy định độ chính xác đo biến động chỉ là một yêu cầu trong quy trình chỉnh lý biến động bản đồ địa chính nói riêng và cơ sở dữ liệu địa chính nói chung. Công tác chỉnh lý biến động đối với CSDL địa chính là vấn đề quan trọng và then chốt trong thời gian sắp tới khi mà đo đạc địa chính chính quy đã phủ kín diện tích và CSDL địa chính đã hoàn thành. Việc quy định như hiện nay về đo đạc biến động chỉnh lý bản đồ địa chính đang còn bất cập, vì vậy bài báo đã đề xuất được quy định về độ chính xác cho đo đạc chỉnh lý biến động các loại đất là rất cần thiết, nhằm giải quyết những vướng mắc và bất cập nảy sinh trong thực tiễn hiện nay. $\bigcirc$

\section{Tài liệu tham khảo}

[1]. Adam Doskocz. About accuracy of analytical determination of areas for cadastre and other purposes. International Conference on 2014.

[2]. Association of Canada Lands Surveyors (ACLS). Manual of Instructions for the Survey of Manual of Instructions for the Survey of Canada LandsRevitalization, Phase 1. 2013.

[3]. United States Department of the Interior Bureau of Land Management Cadastral Survey. Manual of Surveying InstructionsFor the Survey of the Public Lands of the United States. 2009. O

\section{Summary}

\section{Proposed requirements on accuracy in updating cadastral digital map}

Le Viet Nam, Nguyen Thanh Thuy, Nguyen Phi Son

\section{Vietnam Institute of Geodesy and Cartography}

In the measurement of cadastral mapping, it is necessary to distinguish: the accuracy of the measurement of the variation and the accuracy of the data after the measurement to make it compatible with the original data. A fluctuation measurement is a conditional measurement, which achieves the highest area or edge precision by plot coordinates. However, when combined with the original data, this error is affected by the error in the measurement of the establishment and the error of the measurement of fluctuations, because these two data are not the same condition when the next. Revisions can not overlap, especially for digital data. In this article, we will provide a basis for calculating and proposing the accuracy requirements of volumetric measurements and for the sequencing of digital data. This is the practical issue of the regulatory change that is posing to the technical regulator. The results suggested in this paper are the products of the ministerial level project "Research and propose technical requirements in the adjustment of cadastral maps associated with the solution to build cadastral database. $O$ 